\title{
Association Between Plasma Selenium and Glutathione Peroxidase Levels And Severity of Diabetic Nephropathy in Patients With Type Two Diabetes Mellitus
}

\author{
Omid Sedighi ${ }^{1}$; Atieh Makhlough ${ }^{2, *}$; Mohammad Shokrzadeh ${ }^{3}$; Shiva Hoorshad ${ }^{4}$ \\ ${ }_{1}^{1}$ Department of Nephrology, Faculty of Medicine, Imam Khomeini Hospital, Mazandaran University of Medical Sciences, Sari, IR Iran \\ ${ }^{2}$ Diabetes Research Center, Faculty of Medicine, Imam Khomeini Hospital, Mazandaran University of Medical Sciences, Sari, IR Iran \\ ${ }^{3}$ Pharmaceutical Sciences Research Center, Department of Toxicology and Pharmacology, Faculty of Pharmacy, Mazandaran University of Medical Sciences, Sari, IR Iran \\ ${ }^{4}$ Imam Khomeini Hospital, Mazandaran University of Medical Sciences, Sari, IR Iran \\ ${ }^{*}$ Corresponding author: Atieh Makhlough, Diabetes Research Center, Faculty of Medicine, Imam Khomeini Hospital, Mazandaran University of Medical Sciences, Sari, IR Iran. Tel: \\ +98-9111510564, E-mail: makhlough-a@yahoo.com
}

Received: June 19, 2014; Revised: July 6, 2014; Accepted: July 19, 2014

\begin{abstract}
Background: Oxidative stress is thought to be involved in the pathogenesis of diabetic nephropathy. Selenium (Se), and antioxidant enzymes such as glutathione peroxidase (GPx) play an important protective role in diabetes complications.

Objectives: This study aimed to evaluate the association between plasma Se and GPx levels with severity of diabetic nephropathy.

Patients and Methods: In a case-control study, we measured plasma Seand GPx concentrations in patients with type two diabetes without microalbuminuria (group1), with microalbuminuria (group 2), with macroalbuminuria (group 3), and healthy control subjects (group 4). We also assessed plasma glucose, urea, creatinine, and glycated hemoglobin levels in all study patients.

Results: Plasma Se and GPx concentrations were significantly lower in diabetic patients with macroalbuminuria than other study groups $(\mathrm{P}<0.001)$. Albuminuria (Alb/Cr in random urine sample) had a negative correlation with plasma $\mathrm{Se}(\mathrm{r}=-0.40, \mathrm{P}=0.01)$, and $\mathrm{GPx}(\mathrm{r}=-0.23$, $\mathrm{P}=0.03)$ concentrations.

Conclusions: Plasma Se and GPx levels were lower in type two diabetic patients with macroalbuminuria and related to the stage of diabetic nephropathy.
\end{abstract}

Keywords:Diabetes Mellitus, Type 2; Selenium; Glutathione Peroxidase; Albuminuria

\section{Background}

Increased oxidative stress is an important factor in the pathogenesis of diabetic nephropathy(1). Hyperglycemia increases superoxide anion and other reactive oxygen species (ROS) production in patients with diabetes (2). Hyperglycemia also impairs radical scavenging enzymes function, due to lower activity of superoxide dismutase (SOD), glutathione peroxidase (GPx) and catalase (3). Selenium (Se) is an essential component of antioxidant enzymes, especially in GPx structure (4). Selenocysteine is a main part of GPx structure and Se deficiency decreases GPx activity and increases oxidative stress (5). Oxidative damage to protein, DNA, or membrane lipid, leads to cell dysfunction in many tissues (6). There are some studies showing lower plasma Se and GPx levels in patients with diabetes compared to healthy persons (7). GPx depletion may have a main role in the pathogenesis of vascular complications and microalbuminuria by increased oxidative stress (8). Microalbuminuria is the best risk predictor of developing diabetic nephropathy (9). However, the association between plasma Se and GPx levels with albuminuria and severity of diabetic nephropathy in patients with type 2 diabetes mellitus is unclear (10).

\section{Objectives}

This study aimed to investigate the association between plasma Se and GPx levels and albuminuria in patients with type 2 diabetes and compare these results with healthy control subjects.

\section{Patients and Methods}

\subsection{Patients}

This case-control study was conducted in a nephrology clinic center in Sari city, North of Iran from January 2011 to March 2013. Participation of subjects was voluntary. Patients with type 2 diabetes mellitus of both genders and creatinine clearance (was determined by the CockcroftGault formula) $>90 \mathrm{~mL} / \mathrm{min}$ were included in the case groups, and age and sex matched healthy subjects as the control group. Exclusion criteria were age $<30$ or $>60$ years, body mass index $(\mathrm{BMI})>30 \mathrm{~kg} / \mathrm{m}^{2}$, glycated hemoglobin $(\mathrm{HbA1c})>8 \%$, serum creatinine $>1.2 \mathrm{mg} / \mathrm{dL}$, active inflammatory and infectious diseases and other causes of albuminuria such as active urinary tract infection, heavy exercise, and severe congestive heart failure. Then, 
we divided diabetic patients into three groups, based on the severity of albuminuria. Group 1 included 37 patients without microalbuminuria (Albumin/creatinine (Alb/Cr) in a random urine sample $<30 \mathrm{mg} / \mathrm{g}$ ), group 2, 38 patients with microalbuminuria (Alb/Cr in a random urine sample between 30 to $300 \mathrm{mg} / \mathrm{g}$ ), and group 3, 40 patients with macroalbuminuria (Alb/Cr in a random urine sample $>300 \mathrm{mg} / \mathrm{g}$ ).

The Ethics Committee of Mazandaran University of Medical Sciences approved the study and all participants signed an informed consent.

\subsection{Laboratory Studies}

A history including weight and height was taken from each person. BMI was calculated by the Quetelet index formula $\left(\mathrm{BMI}=\mathrm{kg} / \mathrm{m}^{2}\right)$. Ten milliliters of venous blood was taken from every subject after 12 hours fasting to measure plasma glucose, urea, creatinine, HbA1c, Se and GPx levels. Microalbuminuria was assessed in a random sample of urine, by determining Alb/ Cr ratio, using the Micral test method. Plasma glucose, urea and creatinine levels were measured with Pars Azmoon laboratory kits (Tehran, Iran), using the Auto-analyzer BT3000 (Biotechnica, Rome, Italy). HbA1c was determined by high performance liquid chromatography. Plasma Se concentration was assayed by electrothermal atomic absorption spectrometry (ETAAS) using AA240FS appa- ratus (11). Plasma GPx level was determined by Sandwich ELISA kit (UK).

\subsection{Statistical Analysis}

Data analysis was performed using SPSS software (Version 17.0, SPSS Inc., Chicago, Ill, USA). Continuous variables were demonstrated as the mean \pm standard deviation. ANOVA was used to compare the mean value of each parameter between the four groups. Chi-squared and Paired T-test were used to evaluate the quality and quantity parameters, respectively. P value less than 0.05 was considered statistically significant.

\section{Results}

We evaluated 115 patients with type 2 diabetes mellitus and 38 healthy subjects in this study. Table 1 showed basic clinical characteristics of the four groups. Group 1 included 37 diabetic patients without microalbuminuria, group 2, 38 diabetic patients with microalbuminuria, group 3, 40 diabetic patients with macro albuminuria, and group 4,38 healthy subjects as control.

Table 3 showed the results of laboratory tests in four groups. There were no significant differences between the four groups regarding serum creatinine, urea, and glomerular filtration rate (GFR). However, plasma Se and GPx levels were significantly lower in the group 3 than other groups $(\mathrm{P}<0.05)$.

\begin{tabular}{|c|c|c|c|c|c|}
\hline Parameter & Group $1(n=37)$ & Group $2(n=38)$ & $\operatorname{Group} 3(n=40)$ & Group $4(n=38)$ & PValue \\
\hline Age, $y$ & $52.2 \pm 8.1$ & $41.9 \pm 6.2$ & $46.7 \pm 1.3$ & $48.6 \pm 3.8$ & 0.76 \\
\hline Gender & & & & & 0.9 \\
\hline Male & 17 & 19 & 20 & 19 & \\
\hline Female & 20 & 19 & 20 & 19 & \\
\hline BMI, $\mathrm{kg} / \mathrm{m}^{2}$ & $26.2 \pm 2.3$ & $24.1 \pm 1.9$ & $27.4 \pm 2.2$ & $26.1 \pm 1.9$ & 0.88 \\
\hline
\end{tabular}

$\mathrm{a}$ There were no significant differences between the four groups regarding age, sex, and BMI $(\mathrm{P}>0.05)$.

\begin{tabular}{|c|c|c|c|c|}
\hline Parameter & Group $1(n=37)$ & Group $2(n=38)$ & Group $3(n=40)$ & P Value \\
\hline FBS, mg/dL & $175.3 \pm 54.3$ & $190.3 \pm 57.2$ & $226.2 \pm 42.1$ & 0.08 \\
\hline HbA1C & $6.5 \pm 0.6$ & $7.1 \pm 1.6$ & $7.6 \pm 0.5$ & 0.13 \\
\hline Urine Alb/Cr & $16.1 \pm 5.8$ & $136.2 \pm 69.5$ & $546.8 \pm 141.1$ & 0.001 \\
\hline Diabetes mellitus duration, y & $5.2 \pm 2.9$ & $8.2 \pm 2.3$ & $12.3 \pm 3.2$ & 0.02 \\
\hline
\end{tabular}

a There were no significant differences between diabetic patients groups regarding fasting blood sugar (FBS) and HbA1C (P $>0.05)$. However, there were significant differences between the groups regarding random urine $\mathrm{Alb} / \mathrm{Cr}(\mathrm{P}=0.001)$ and diabetes mellitus duration $(\mathrm{P}=0.02)$.

\begin{tabular}{|c|c|c|c|c|c|}
\hline Parameter & Group $1(n=37)$ & Group $2(n=38)$ & $\operatorname{Group} 3(n=40)$ & Group $4(n=38)$ & P Value \\
\hline Urea, mg/dL & $31.4 \pm 6.3$ & $33.2 \pm 3.8$ & $32.6 \pm 4.7$ & $29.2 \pm 6.7$ & 0.19 \\
\hline Creatinine, mg/dL & $0.92 \pm 0.14$ & $0.87 \pm 0.36$ & $1.12 \pm 0.61$ & $0.85 \pm 0.45$ & 0.09 \\
\hline $\mathrm{GFR}, \mathrm{mL} / \mathrm{min}$ & $96 \pm 27$ & $106 \pm 33$ & $92 \pm 25$ & $108 \pm 41$ & 0.07 \\
\hline Plasma Se, $\mu \mathrm{g} / \mathrm{L}$ & $56.85 \pm 10.68$ & $39.7 \pm 8.04$ & $29.8 \pm 6.8$ & $76.9 \pm 11.58$ & 0.0001 \\
\hline Plasma GPx, ng/mL & $28.2 \pm 5.27$ & $23.7 \pm 4.34$ & $17.61 \pm 4.66$ & $32.2 \pm 4.1$ & 0.0001 \\
\hline
\end{tabular}

\footnotetext{
${ }^{\mathrm{a}}$ There were significant negative correlations between urine Alb/Cr with plasma Se $(r=-0.40, P=0.01)$ and plasma GPx $(r=-0.23, P=0.03)$ concentrations.
} 


\section{Discussion}

Plasma Se and GPx concentrations were significantly lower in type 2 diabetic patients with macroalbuminuria than other diabetic patients and healthy subjects. Moreover, we found a negative correlation between albuminuria and plasma Se and GPx levels. Increased oxidative stress and glycosylation play a main pathogenic role in diabetic endothelial cell dysfunction (12). Several experimental studies evaluated antioxidant status in diabetic nephropathy $(12,13)$. There is a positive correlation between plasma Se concentration and cellular GPx activity in different tissues (14). Kornhauser et al. reported a negative correlation between microalbuminuria with plasma Se and GPx concentrations in type two diabetic patients (7). Plasma GPx level was lower in diabetic patients with microalbuminuria than those without microalbuminuria or control subjects. However, in another study, plasma Se concentration was not associated with microalbuminuria among American adults (15). In this study, patients with microalbuminuria had reduced concentrations of selected antioxidants such as lycopene and $\beta$-cryptoxanthin. Mahmoud Parham et al. showed that zinc supplementation reduced albuminuria in type 2 diabetic patients with microalbuminuria (16). Zinc and melatonin or magnesium also decreased albuminuria in patients with diabetes in other studies $(17,18)$. These renal protective effects of zinc may be due to increased synthesis of antioxidant enzymes such as GPx and superoxide dismutase (19). As well, in another study, Se supplementation was effective to increase cellular GPx activity in patients with different stages of chronic kidney disease (20). It is unclear how microalbuminuria increases cardiovascular risks or renal failure progression (15). In one study, microalbuminuria was related to proximal tubule injury and loss of glomerular filtration barrier integrity (21). As well, microalbuminuria is a marker of endothelial cell dysfunction due to numerous factors, including inflammation, insulin resistance, and oxidative stress $(22,23)$. Ozdemir et al. reported that diabetic patients with microalbuminuria had significantly lower serum GPx level compared to healthy subjects (24). Finally, our study had some limitations. First, we did not measure cellular GPx activity in our patients. However, other studies have shown that oxidative stress is associated with cellular GPx activity in patients with diabetes (25). Second, we did not analyze plasma Se and GPx levels in diabetic patients with renal failure. Some studies suggested that Se supplementation might decrease oxidative stress and progression of chronic kidney disease $(20,26)$. In summary, this study showed that plasma Se and GPx concentrations were significantly and negatively associated with the severity of diabetic nephropathy in patients with type 2 diabetes mellitus. More studies are needed to determine the association between plasma Se and GPx levels with renal failure progression in these patients.

\section{Acknowledgements}

This article was extracted from the general medical thesis of Shiva Hoorshad with the ID number 90-152. The authors would like to thank Tooba clinic officers for their cooperation in our study.

\section{Authors' Contributions}

Omid Sedighi: chief manager; Atieh Makhlough: consultant and correspondence; Mohammad Shokrzadeh: laboratory test consultant; Shiva Hoorshad: data collector.

\section{Funding/Support}

This study was supported by a grant from Mazandaran University of Medical Sciences Research Center.

\section{References}

1. Martin-Gallan P, Carrascosa A, Gussinye M, Dominguez C. Oxidative stress in childhood type 1 diabetes: Results from a study covering the first 20 years of evolution. Free Radic Res. 2007;41(8):919-28.

2. Pricci F, Leto G, Amadio L, Iacobini C, Cordone S, Catalano S, et al. Oxidative stress in diabetes-induced endothelial dysfunction involvement of nitric oxide and protein kinase C. Free Radical Biol Medic. 2003;35(6):683-94.

3. Firoozrai M, Nourbakhsh M, Razzaghy-Azar M. Erythrocyte susceptibility to oxidative stress and antioxidant status in patients with type 1 diabetes. Diabetes Res Clin Pract. 2007;77(3):427-32.

4. Zachara BA, Gromadzinska J, Wasowicz W, Zbrog Z. Red blood cell and plasma glutathione peroxidase activities and selenium concentration in patients with chronic kidney disease: a review. Acta Biochim Pol.2006;53(4):663-77.

5. Beytut E, Erisir M, Aksakal M. Effects of additional vitamin E and selenium supply on antioxidative defence mechanisms in the kidney of rats treated with high doses of glucocorticoid. Cell Biochem Funct. 2004;22(1):59-65.

6. Afshari AT, Shirpoor A, Farshid A, Saadatian R, Rasmi Y, Saboory $\mathrm{E}$, et al. The effect of ginger on diabetic nephropathy, plasma antioxidant capacity and lipid peroxidation in rats. Food Chem. 2007;101(1):148-53.

7. Kornhauser C, Garcia-Ramirez JR, Wrobel K, Perez-Luque EL, Garay-Sevilla ME, Wrobel K. Serum selenium and glutathione peroxidase concentrations in type 2 diabetes mellitus patients. Prim Care Diabetes. 2008;2(2):81-5.

8. Darmaun D, Smith SD, Sweeten S, Sager BK, Welch S, Mauras N. Evidence for accelerated rates of glutathione utilization and glutathione depletion in adolescents with poorly controlled type 1 diabetes. Diabetes. 2005;54(1):190-6.

9. Abdeyazdan Z, Hashemipour M, Hasanzadeh A, Pour Naghshban Z, Kabirzadeh M. Microalbuminuria in type 1 diabetes mellitus. . Shiraz E-Medic J. 2007;8(1):28-32.

10. Aslan M, Sabuncu T, Kocyigit A, Celik H, Selek S. Relationship between total oxidant status and severity of diabetic nephropathy in type 2 diabetic patients. Nutr Metab Cardiovasc Dis. 2007;17(10):734-40.

11. Gardiner PHE, Littlejohn D, Halls DJ, Fell GS. Direct Determination of Selenium in Human Blood Serum and Plasma by Electrothermal Atomic Absorption Spectrometry. Trace Elem Med Biol J. 1995;9(2):74-81.

12. Hernandez-Marco R, Codoner-Franch P, Pons Morales S, Del Castillo Villaescusa C, Boix Garcia L, Valls Belles V. Oxidant/antioxidant status and hyperfiltration in young patients with type 1 diabetes mellitus. Pediatr Nephrol. 2009;24(1):121-7.

13. Aliciguzel Y, Ozen I, Aslan M, Karayalcin U. Activities of xanthine oxidoreductase and antioxidant enzymes in different tissues of diabetic rats. Lab Clin Med J. 2003;142(3):172-7.

14. Beckett GJ, Arthur JR. Selenium and endocrine systems.J Endocrinol. 2005;184(3):455-65. 
15. Ford ES, Giles WH, Mokdad AH, Ajani UA. Microalbuminuria and concentrations of antioxidants among US adults. Am J Kidney Dis. 2005;45(2):248-55.

16. Parham M, Amini M, Aminorroaya A, Heidarian E. Effect of zinc supplementation on microalbuminuria in patients with type 2 diabetes: a double blind, randomized, placebo-controlled, crossover trial. Rev Diabet Stud. 2008;5(2):102-9.

17. Farvid MS, Jalali M, Siassi F, Hosseini M. Comparison of the effects of vitamins and/or mineral supplementation on glomerular and tubular dysfunction in type 2 diabetes. Diabetes Care. 2005;28(10):2458-64.

18. Kadhim HM, Ismail SH, Hussein KI, Bakir IH, Sahib AS, Khalaf $\mathrm{BH}$, et al. Effects of melatonin and zinc on lipid profile and renal function in type 2 diabetic patients poorly controlled with metformin. J Pineal Res. 2006;41(2):189-93.

19. Maret W, Sandstead HH. Zinc requirements and the risks and benefits of zinc supplementation. J Trace Elem Med Biol. 2006;20(1):3-18.

20. Sedighi O, Zargari M, Varshi G. Effect of selenium supplementation on glutathione peroxidase enzyme activity in patients with chronic kidney disease: a randomized clinical trial. Nephrourol Mon. 2014;6(3)

21. Hayden MR, Chowdhury NA, Witte L, Sowers JR. Microalbumin- uria and Proximal Tubule Remodeling in the Cardiometabolic Syndrome. CardioMetab Syndrome J. 2006;1(2):107-14.

22. Murtaugh MA, Jacobs DR, Jr, Yu X, Gross MD, Steffes M, Coronary Artery Risk Development in Young Adults S. Correlates of urinary albumin excretion in young adult blacks and whites: the Coronary Artery Risk Development in Young Adults Study. Am J Epidemiol. 2003;158(7):676-86.

23. Valgimigli M, Merli E, Malagutti P, Soukhomovskaia O, Cicchitelli G, Macri G, et al. Endothelial dysfunction in acute and chronic coronary syndromes: evidence for a pathogenetic role of oxidative stress. Arch Biochem Biophys. 2003;420(2):255-61.

24. Ozdemir G, Ozden M, Maral H, Kuskay S, Cetinalp P, Tarkun I Malondialdehyde, glutathione, glutathione peroxidase and homocysteine levels in type 2 diabetic patients with and without microalbuminuria. Ann Clin Biochem. 2005;42(Pt 2):99-104

25. Waggiallah $\mathrm{H}$, Alzohairy M. The effect of oxidative stress on human red cells glutathione peroxidase, glutathione reductase level, and prevalence of anemia among diabetics. N Am J Med Sci. 2011;3(7):344-7.

26. Zachara BA, Gromadzinska J, Palus J, Zbrog Z, Swiech R, Twardowska E, et al. The effect of selenium supplementation in the prevention of DNA damage in white blood cells of hemodialyzed patients: a pilot study. Biol Trace Elem Res. 2011;142(3):274-83. 